\title{
Afetividade, território e vulnerabilidade na relação pessoa-ambiente: um olhar ético político ${ }^{\star}$
}

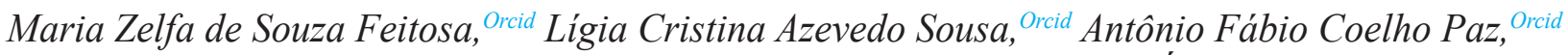

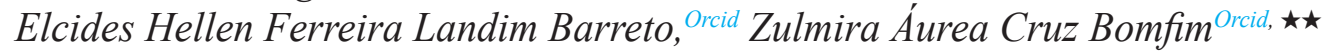 \\ Universidade Federal do Ceará, Fortaleza, CE, Brasil
}

Resumo

Este artigo objetiva dialogar os conceitos território e vulnerabilidade, a partir da categoria afetividade, fundamentados na Psicologia Ambiental e na psicologia social de base psicossocial e histórico-cultural, ao buscar uma compreensão dialética da inter-relação pessoa-ambiente. Como eixo de observação, investigação e análise, a afetividade subsidia uma perspectiva ética de transformação social, em territórios vulneráveis, como fio condutor de estratégias de enfrentamento e proposição de políticas de proteção a populações submetidas às desigualdades. Indicamos algumas intervenções oriundas de reflexões teórico-práticas que possibilitam compreender os afetos como potencializadores dos sujeitos, pela implicação destes com territórios e coletividades, rumo a processos emancipatórios humanos.

Palavras-chave: psicologia ambiental; território; vulnerabilidade; afetividade.

\section{Affectiviness, territory and vulnerability in the person-environment interrelationship: a political ethical vision}

\begin{abstract}
This article aims to discuss the concepts of territory and vulnerability, based on the affectivity category, based on Environmental Psychology and on social psychology with a psychosocial and historical-cultural basis, when It seeks a dialectical understanding of the person-environment interrelationship. As an axis of observation, investigation and analysis, affectivity subsidizes an ethical perspective of social transformation in vulnerable territories as the guiding thread of coping strategies and proposing policies to protect populations subjected to inequalities. We indicate some interventions derived from theoretical-practical reflections that make it possible to understand the affections as potentializers of the subjects, by the implication of these with territories and collectivities, towards human emancipation processes.
\end{abstract}

Keywords: environmental psychology; territory; vulnerability; affection.

\section{Introdução}

A Psicologia Ambiental, apesar de algumas controvérsias acerca de sua caracterização e de apresentar um conjunto de definições gerais com limites imprecisos, que têm por preocupação não comprometer essa disciplina (ARAGONÉS; AMÉRIGO, 1998) com reducionismos arbitrários, pode ser compreendida, segundo Pinheiro, Günther e Guzzo (2014), como o estudo das inter-relações entre o ser humano e seu ambiente sócio-físico, considerando-se aí os aspectos individuais e coletivos que os perpassam. Concebe-se que, nessas inter-relações, ao transformar seu entorno, o ser humano é, também, transformado por ele (ITTELSON et al., 2005). Debruçando-se sobre essas questões, a Psicologia Ambiental sustenta-se numa perspectiva interdisciplinar, constituindo-se dos saberes provenientes de áreas como a Psicologia, a Arquitetura, o Urbanismo, a Geografia, as Ciências Ambientais, entre outros campos afins, uma vez que são múltiplos os olhares necessários para dar conta do entendimento dos aspectos físicos, sociais, culturais e simbólicos envolvidos nestas inter-relações.

*Agências de fomento: Coordenação de Aperfeiçoamento de Pessoal de Nível Superior (CAPES) e Fundação Cearense de Apoio ao Desenvolvimento Científico e Tecnológico (Funcap)

${ }^{\star \star}$ Endereço para correspondência: Universidade Federal do Ceará, Centro de Humanidades, Departamento de Psicologia. Avenida da Universidade 2762 - Benfica - Fortaleza, CE - Brasil. CEP: 60020-180. E-mail: maria.zelfa@ hotmail.com, ligiacasousa@gmail.com, afabiocpaz@gmail.com, hellenbarreto0@hotmail.com, zulaurea@gmail.com
Em pesquisas recentes (BOMFIM, 2010; BOMFIM et al., 2013; BOMFIM et al., 2014; FEITOSA, 2014; MARTINS, 2015), foram desenvolvidas articulações entre a Psicologia Ambiental e a Psicologia Social de bases psicossocial e histórico-cultural, nas quais tem se estruturado contribuições importantes para pensarmos a inter-relação do sujeito com o ambiente a partir dos afetos. A Psicologia Social a qual nos referimos, conforme Lane (1984, p. 19), objetiva "[...] conhecer o Indivíduo no conjunto de suas relações sociais, tanto naquilo que lhe é específico como naquilo em que ele é manifestação grupal e social [...]”. A concepção de afetividade é de contribuição da filosofia espinosana, na qual os afetos referem-se a como corpo e mente, sendo estes uma e a mesma coisa, afetam e são afetados por outros corpos, de maneira que sua potência de ação pode ser aumentada, o que viabiliza a ação livre no mundo, ou diminuída, o que conduz à passividade (SPINOZA, 2015).

Tendo como base essa perspectiva afetiva e social da relação pessoa-ambiente, este artigo objetiva rever os conceitos de território e vulnerabilidade, a partir de contribuições da afetividade espinozana.

É a partir deste olhar dialético que desdobramos os estudos sobre território, tendo em vista suas inter-relações com as questões referentes à vulnerabilidade, tomando-os não apenas na condição de conceitos, mas também como objetos de intervenção. Este propósito justifica-se por reconhecermos a importância da construção 
de estratégias que fomentem os processos de transformação social (LANE, 1984), caracterizando uma Psicologia Ambiental que assume um compromisso ético-político em suas pesquisas e atuação profissional.

Essa Psicologia Ambiental, referenciada na Psicologia Social, traz a afetividade como uma categoria integradora, para orientar os estudos das inter-relações pessoa-ambiente, buscando superar tradicionais dicotomias entre razão e emoção, sujeito e objeto. Por afetividade entendemos a implicação do sujeito com o outro e com o mundo (HELLER, 1993). Sendo ela uma dimensão inalienável do ser humano, Sawaia (2011) a define como uma categoria analítica que resguarda a capacidade de desestabilizar o que está hegemonicamente posto, proporcionando, assim, a transformação social e a possibilidade de falar do humano em sua inteireza, já que para Spinoza (2015), não existe separação entre afeto e razão.

Apoiados nisso, consideramos que olhar território e vulnerabilidade, a partir da afetividade, pode contribuir para a melhor compreensão dos modos pelos quais o sujeito se relaciona com os ambientes, construídos ou não, seu modo de implicar-se com a realidade e como isso afeta a Estima de Lugar (BOMFIM, 2010), entendida como a avaliação afetiva do ambiente, voltada para sentimentos e emoções ligadas a este.

Respaldando-se em uma concepção dialética da relação entre a pessoa e o ambiente, a Estima de Lugar é definida por Bomfim (2010, p. 218) como

[...] uma forma específica de conhecimento, relativa ao aspecto de significado ambiental na dimensão de emoções e sentimentos sobre o ambiente construído. Como categoria social, a estima pode ser compreendida como uma forma de pensamento social que caminha em paralelo a outros de simbolismo do espaço, derivado da categoria de identidade social urbana ou de uma afetividade do lugar.

Desta maneira, expressa as dimensões afetivas e indica os mecanismos de potencialização ou de despotencialização da ação do sujeito. Estes processos remetem a indicadores afetivos que envolvem desde características individuais como a autoestima, a autoeficácia e a perspectiva de futuro até a construção de uma rede de apoio social com base em relações comunitárias, promovendo as condições necessárias para a diminuição de vulnerabilidades e expandindo a potência de ação (BOMFIM, 2010).

\section{Psicologia ambiental e afetividade}

A relação do ser humano com o ambiente é de ordem física e simbólica, os espaços são multidimensionais e compartilham da mesma materialidade e subjetividade que os seres humanos (SAWAIA, 1995). Na identificação com os espaços o sujeito pode construir sua subjetividade, significando a si próprio e à sua vida (MOSER, 1998). Tuan (1983) diferencia os espaços dos lugares, de maneira que o espaço relaciona-se ao movimento e à liberdade de transitar no ainda não familiar, à amplitude, às grandes dimensões, o que pode, inclusive, gerar certo sentimento de insegurança frente ao desconhecido. Os lugares, por outro lado, são concebidos como espaços dotados de valor, tornam-se significativos (CORRALIZA,
1998), remetem à segurança do que é conhecido, familiar, nele o sujeito pode satisfazer suas necessidades biológicas e afetivas, conhece-o com todos os seus sentidos e com a mente ativa e reflexiva, dentro de um processo cognitivo e afetivo (TUAN, 1983).

Em alguns casos, tanto nos espaços como nos lugares, os sujeitos podem ser afetados por algum tipo de vulnerabilidade, a qual se apresenta como um conceito multidimensional, definido comumente a partir dos riscos e perigos a que o sujeito ou grupo está exposto em um contexto geográfico e social específico (MARADOLA JR.; HOGAN, 2006), sua incapacidade de reagir frente a essas adversidades e a dificuldade em adaptar-se frente à materialidade da situação de risco (VÉRAS, 2010). Para Abramovay et al. (2002, p. 13), ela é o

[...] resultado negativo da relação entre a disponibilidade dos recursos materiais ou simbólicos dos atores, sejam eles indivíduos ou grupos, e o acesso à estrutura de oportunidades sociais, econômicas, culturais que provêm do Estado, do mercado e da sociedade.

Partindo da Psicologia Ambiental, debruçamo-nos sobre a discussão acerca da dimensão espacial da vulnerabilidade, ou seja, dos territórios em que a vulnerabilidade se concretiza. A escolha por essa disciplina como embasamento teórico deste artigo inclui suas contribuições tanto acerca do território, quanto da vulnerabilidade, partindo do interesse em investigar os fenômenos que surgem a partir das inter-relações entre os sujeitos e os ambientes. A demanda por estudar tais conexões tornou-se indispensável diante do cenário de crise ambiental agravada pela valorização de uma cultura de consumo como condição para o alcance do desenvolvimento nos moldes capitalistas. A prosperidade econômica é priorizada em detrimento do bem-estar social e, ainda, do cuidado com a natureza.

Aqui, vemos que a lógica do consumo pressupõe que o ambiente seja encarado de forma utilitária, considerado como mais um recurso, tal como os financeiros e humanos. São desconsideradas, portanto, as propriedades ambientais do ser humano e da vida em sociedade, organizadas a partir das interações pessoa-ambiente, que tanto envolvem relações de poder, quanto ligações afetivas e simbólicas. Concordamos com Corraliza (1998) quando afirma que o ambiente é um território emocional, ele viabiliza informações que definem a interação do sujeito com o lugar, nele os sujeitos podem satisfazer suas necessidades biológicas, simbólicas e emocionais, acessando-o cognitiva e afetivamente.

Como resposta às preocupações com a possibilidade do esgotamento da vida no planeta, devido à extração desenfreada de recursos naturais e aos consequentes impactos ambientais daí decorrentes, são reunidas as colaborações de diversas áreas do conhecimento, tais como Geografia, Sociologia, Antropologia, Ciências Ambientais, entre outras, no sentido de apontar alternativas frente aos desafios de promover um desenvolvimento sustentável. 
$\mathrm{Na}$ Psicologia o interesse pelo ambiente era algo visualizado, principalmente, na Psicologia do Desenvolvimento e na Psicologia Social, mas de modo secundário. Com o advento destas preocupações e o envolvimento das áreas acima, a temática ganhou destaque, contribuindo com o desenvolvimento da Psicologia Ambiental. Diferentemente de outras áreas, este campo se volta ao estudo das relações recíprocas entre a pessoa e o ambiente, sendo desenvolvido em diálogo com as outras ciências mencionadas, admitindo o ambiente como espaço sócio-físico. Tem interesse de investigar estes fenômenos numa perspectiva interdisciplinar, considerando que os diversos olhares sobre o ambiente, como construção social e simbólica, abrem possibilidades de interlocuções em busca de um compromisso ético de reflexão e transformação das problemáticas socioambientais. Assim, a Psicologia Ambiental propõe o diálogo com o saber proveniente de uma nova racionalidade ambiental, que não separe razão de emoção e, portanto, sujeito de objeto (ALENCAR; BOMFIM; BARROCAS, 2010).

É do encontro entre a Psicologia Ambiental e a Psicologia Social laneana, a qual se assenta em uma postura materialista-histórica-dialética (SAWAIA, 2002), que se constrói uma Psicologia Ambiental de base psicossocial e histórico-cultural, que também se debruça sobre as questões ambientais, porém a partir de uma perspectiva do ser humano como produto histórico-social, aquele que constrói e transforma a sociedade por ele construída, conforme defende Lane (1984). Essa visão histórica do homem também é aplicada aos ambientes, que são considerados construções sociais, produtos da intervenção humana e produtores dela.

Assim, a ideia de que o homem age sobre os ambientes implica, consequentemente, uma contínua transformação de ambos. Neste sentido, esta área de conhecimento considera que o ambiente também constitui nossa identidade, conforme desenvolveu Proshansky, Fabian e Kaminoff (1983) com o conceito de identidade de lugar, na medida em que a identidade relaciona-se não apenas à identificação com os lugares, mas também à vinculação afetiva e transformadora na relação com o ambiente.

Um dos processos mais importantes da interação indivíduo-ambiente está relacionado à conversão do espaço físico em espaço significativo para o indivíduo, considerando-se que o ambiente tem a característica de ser um território emocional (CORRALIZA, 1998). Nesse sentido, Bomfim (2003) acrescenta que, embora associados a conteúdos intelectuais, valores e representações, os sentimentos são configurações afetivas mais estáveis, sendo menos reativos a estímulos passageiros. Assim, a afetividade revela como os indivíduos agem e se posicionam no espaço, além de obter conhecimento sobre o ambiente. Ela é também a via pela qual o sujeito identifica-se com o ambiente, de onde derivam os laços afetivos que as pessoas criam com os lugares, necessitando estarem próximas a ele, à medida que estes lugares apresentam recursos físicos, biológicos, emocionais, etc., que suprem suas necessidades (GIULIANI, 2004).
Apesar desta importância de se considerar as dimensões afetiva e cognitiva como indissociáveis, tradicionalmente, os estudos em Psicologia partem do pressuposto da dicotomia racionalidade versus afetividade, de modo que os afetos estariam mais próximos do caráter irracional da condição humana. Segundo Ponte (2010), caberia à racionalidade regulamentar o uso da afetividade e promover a domesticação dos afetos para atender à lógica de organização da sociedade ocidental contemporânea.

Em contraponto a uma visão dualizante da subjetividade, Spinoza (2015) defende que a razão e o afeto imbricam-se mutuamente na ação humana. Para este autor, a pessoa é uma unidade integral. Mente e corpo são modos diferentes de uma única e infinita substância, impossibilitando a supremacia de um sobre o outro. Cabe ressaltar, também, a posição de Vigotski (1998), que, pela mesma concepção, era contra o estudo dos fenômenos psicológicos embasados na segregação entre comportamento e psique. Para ele, ação e comportamento proviam de uma base afetivo-volitiva, dado que:

O pensamento propriamente dito é gerado pela motivação, isto é, por nossos desejos e necessidades, nossos interesses e emoções. [...] Uma compreensão plena e verdadeira do pensamento de outrem só é possível quando entendemos sua base afetivo-volitiva. (VIGOTSKI, 1998, p. 187).

Embasada por esses autores, Sawaia (2011) elege a afetividade como categoria ética e política fundamental na constituição da identidade, busca da felicidade e apropriação dos territórios. Para a autora, a potencialização dos sujeitos, ou seja, o aumento de sua potência de ação, está relacionada ao desenvolvimento de valores éticos na forma de sentimentos, desejos e necessidades, pois a ética é compreendida como " [...] a capacidade do corpo e do pensamento em selecionar, nos encontros, o que permite ultrapassar as condições de existência na direção da felicidade, como um aprendizado contínuo" (SAWAIA, 2003, p. 59). Assim sendo, o aumento ou diminuição dessa capacidade se dá pela via dos afetos. Parte-se, portanto, da consideração de que a afetividade não deve ser estudada de forma apartada da ética ou da razão, mas como dimensão fundamental na construção da ação e da subjetividade humana (PONTE, 2010).

Assim, o tratamento do ambiente não deve estar desvinculado do investimento afetivo e das relações subjetivas que são compartilhadas neste. Dessa forma, a afetividade aparece como categoria fundamental para se compreender as inter-relações pessoa-ambiente. Por isso, também importante para entender o território e as condições de vulnerabilidade.

\section{O lugar da afetividade na discussão do território e da vulnerabilidade}

A primeira área a se interessar em conceituar o território foi a Biologia. Valdiviesso (2006, p. 15) apresenta uma definição de território a partir de alguns autores dessa área: "Um território é um espaço delimitado, controlado e defendido, com algum dispêndio de energia, de forma a assegurar as possibilidades de exploração exclusivas". 
O autor mostra como a maior capacidade de agregação traz a uma espécie vantagens para obtenção de alimentos e menor vulnerabilidade a predadores.

Hall (1966) desenvolveu estudos com grupos de ratos no meio urbano e no seu habitat natural, verificando que a maior organização territorial beneficia a sobrevivência e a perpetuação dos indivíduos. Ele verificou que quando os grupos apresentaram menos disputas pela liderança do bando, o que se conseguiu através de uma ocupação mais organizada em defesa do território, as fêmeas passaram por gestações mais saudáveis e cuidaram melhor dos filhotes.

De acordo com Valdiviesso (2006) e Hall (1966), encontramos mesmo na Biologia alguma forma de aproximação entre vulnerabilidade e território, no sentido de ambos relacionarem as características ambientais do espaço à organização coletiva dos indivíduos.

Essa concepção naturalista da Biologia foi tomada como orientadora dos primeiros estudos da Geografia acerca do tema, porém foi acrescida uma visão mais materialista do território, que privilegiava quase exclusivamente aspectos físicos. Esses trabalhos foram duramente criticados, ou por fazerem uma associação demasiado estreita entre a territorialidade humana e a territorialidade animal, ou por desconsiderem a cultura e os fatores sociais, sendo em extremo restrita ao espaço físico (HAESBAERT, 2004).

Um breve estudo etimológico do termo território, realizado por Haesbaert (2004), mostra que, apesar de encontrar algumas divergências entre as origens da palavra, seu campo semântico é relativo a dois sentidos: terra e aterrorizar. Terra referindo-se à delimitação de parte do espaço geográfico, à materialidade do território, que fala de apropriação simbólica ou material de uma porção de terra. Aterrorizar diz respeito aos sentimentos que o território inspira, como de proteção e o pavor de ser excluído, devendo ser aterrorizados os que desejam invadi-lo. O autor constata que os dois sentidos em alguma medida estão presentes nas muitas definições e nos debates sobre território.

Entretanto, percebemos que a dimensão afetiva da conceituação de território quando não é negligenciada, geralmente desconsidera o potencial transformador da relação afetiva com os lugares. Haesbaert (2004, p. 71) analisa as várias influências históricas e filosóficas em torno do estudo do território, concluindo que entre as diferentes visões acerca das dimensões cultural e social do espaço: “A abordagem utilitarista do território não dá conta dos principais conflitos do mundo contemporâneo". Dito de outro modo, enfocar o território somente pela via de seus recursos relacionados a necessidades biológicas e mercadológicas, a um uso meramente racional de seus espaços, não compreende toda a complexidade territorial em sua multidimensionalidade micro e macrossocial.

Por isso o território deve ser concebido a partir da integração de suas múltiplas dimensões: natural, econômica, política e cultural, na medida em que este abrange toda a história humana, como um dos componentes ontológicos de sua formação.
Nesse sentido, acreditamos que a afetividade é a via integradora para a compreensão do território e de suas vulnerabilidades, pois ela é referência para não dicotomizar o olhar lançado sobre as relações entre o homem e os ambientes, mas percebê-las potencializadoras da ação ou produtoras de desigualdades sociais.

Nossa proposta concorda com Haesbaert (2004), o qual sugere que o território seja visto a partir da concepção do espaço como um híbrido entre sociedade, natureza, política, economia, cultura, materialidade e idealidade, onde as relações formadas em meio a estes fatores são, muitas vezes, produtoras de desigualdades sociais que resultam em situações de vulnerabilidade.

Assim se configuram as vulnerabilidades nos territórios, a partir do jogo de interesses, o que foi denunciado pelo geógrafo Milton Santos (1926-2001), teórico e militante contrário à exclusão socioespacial decorrente da ocupação desigual do solo. O autor percebe que os mais poderosos delimitam a posse e o uso dos espaços, produzindo desigualdades sociais (SANTOS 2005).

Santos (1999) faz uma distinção entre o que significa território para os atores hegemônicos e para os homogeneizados. O primeiro grupo é representado pelos que detém o poder sobre os recursos, para eles o território usado é visto como o que pode responder aos seus interesses particulares. Para os homogeneizados, o território usado é abrigo, onde eles recriam estratégias para a garantia da sobrevivência.

Para o autor, é o uso, e não o território em si que faz deste um objeto de análise social, a partir disso se denuncia como os processos econômicos capitalistas, pelas transformações da chamada globalização, distorcem a organização e reorganização dos territórios e a vida das populações. O território é então uma produção socioespacial (SANTOS, 2005).

As concepções de Milton Santos sobre território tornaram-se grande referência no campo das políticas públicas de saúde para discutir possibilidades de atuação sobre contextos de vulnerabilidade, principalmente por denunciar as desigualdades presentes no território, destacando como os diversos atores sociais se apropriam dele (SANTOS, 2005).

Quando compreendemos melhor essa complexa categoria que é o território, temos condições de ver a vulnerabilidade de maneira plural, observando que as relações produtoras das vulnerabilidades não estão apenas nos sujeitos ou nos espaços. Entre o ambiente físico e o homem existe uma cultura, uma ideia, concepções de caráter subjetivo que influenciam as maneiras como concebemos o território, vivemos nele e se produzem as vulnerabilidades.

O conceito de vulnerabilidade abrange uma série de qualificações, cujas definições apresentam especificidades. Entretanto, estas concepções, fomentadas em diversas áreas do conhecimento, trazem em comum o fato de que a vulnerabilidade está sempre ocorrendo no território onde as pessoas vivem. Neste sentido, Zanella, Dantas e Olímpio (2011, p. 15) afirmam que: 
[...] o estudo da vulnerabilidade, e sua espacialização em determinado território, possibilita a identificação das áreas a apresentar possíveis impactos ambientais, constituindo-se em ferramenta importante ao planejamento ambiental e ordenamento territorial.

No presente artigo, compreendemos que esta definição é ainda mais complexa, uma vez que a vulnerabilidade atravessa, inclusive, a inter-relação pessoa-ambiente, a qual se constitui como um grande ponto de interesse da Psicologia Ambiental (PINHEIRO; GÜNTHER; GUZZO, 2014).

A relação socioespacial que ocorre muitas vezes sem verbalizações e nem sempre é percebida pelos indivíduos, é marcada pelas concepções e contradições do mundo capitalista, globalizado, que produz relações injustas e desiguais, orientadas a hegemonizar uma cultura em detrimento de outras consideradas subalternas (SANTOS, 1999).

Estes fenômenos estão atrelados à segregação e ao cerceamento da cidadania, que geram o que Sawaia (2011) nomeia de sofrimento ético-político, ou seja, o sofrimento originado a partir das relações de submissão, de desigualdade e da dialética inclusão-exclusão muitas vezes veladas pela aparente integração social.

Sawaia (2003) aponta, ainda, que a tentativa de manter a ordem dos espaços, especialmente os urbanos, está submetida à ideologia político-econômica de dominação, que visa a administrar a desigualdade social. Reportando-se a esta desigualdade, a autora afirma que o território é um lugar de contrastes, ao mesmo tempo em que pode propiciar a identificação entre os pares, gestando formas novas de sociabilidade, mais afetivas e libertárias, pode ser também excludente e gerador de sofrimento (SAWAIA, 1995).

Tal quadro se constitui no que Wisner (1998) entende por vulnerabilidade, em que, diante de eventos extremos que causam intenso sofrimento, a capacidade dos sujeitos para lidarem com as situações estressantes pode ser diminuída pela falta de acesso a informações, bens e serviços, crédito financeiro, suporte social, entre outros, deixando estas pessoas mais propensas à situação de risco, mortalidade e de intensificação desta falta de acesso. Conforme o autor supracitado, todos esses fatores, sejam físicos, subjetivos ou sociais ocorrem em um território determinado, fruto de um dado processo histórico e cultural, que não se limita aos espaços institucionalmente delimitados, mas são desenhados a partir dos processos de apropriação do espaço.

Pol (1996, p. 45) defende que a apropriação do espaço "[...] con toda su complejidad - aparece como uno de los núcleos centrales en la interacción entre el ser humano (H) y su entorno físico (E)". Esse processo relaciona-se à necessidade humana de deixar marcas no território, seja de maneira mais rudimentar ou sofisticada, criando assim referências capazes de proporcionar orientação, preservação da identidade frente a si e aos demais, bem como permitindo ao sujeito dotar de sentido o espaço. Deste modo,

Identidad y pertinencia, privacía e intimidad, ser causa y a su vez dejarse llevar por sus referentes..., constituyen la clave de la creación y la asumción de un universo de significados que constituyen la cultura y el entorno del sujeto, fisicalizado a través del tiempo en un espacio 'vacío' que deviene un 'lugar' con sentido. Es lo que llamamos apropiación (POL, 1996, p. 45).

Aqui, compreendemos que as dinâmicas afetivas devem perpassar o entendimento do uso e da ocupação do território, uma vez que os afetos são, muitas vezes, negligenciados na dinâmica de acumulação capitalista ou gerenciados a favor do sistema econômico vigente (HELLER, 1993), de maneira que sejam manipuladas e expostas apenas as emoções e os sentimentos capazes de gerar lucro e o distanciamento necessário ao consumo. Este jogo político e econômico justifica a sobreposição do território no seu sentido de posse utilitarista e funcional, em detrimento dos aspectos subjetivos da apropriação do lugar, tal como fora descrito por Pol (1996), que apresenta os aspectos simbólicos e comportamentais da identificação com os lugares.

Como um modo de resistência a essa visão fragmentada do território, é preciso chamar atenção para o uso que os sujeitos fazem dele, para a espacialidade da vulnerabilidade, que se expressa, inclusive, no modo de organização dos espaços, estando diretamente relacionada às questões econômicas, políticas, sociais e ideológicas que compõem os territórios (SANTOS, 1999). Um exemplo desta constatação é apresentado por Véras (2010), que chama atenção para a formação das cidades capitalistas, as quais estão sendo construídas de acordo com os interesses de acumulação do capital, gerando uma apropriação privada daquilo que é produzido coletivamente e viabilizando uma organização urbana pautada na segregação socioespacial, que separa zonas destinadas aos que têm uma alta renda e espaços de moradias degradados aos pobres e miseráveis.

Nos estudos sobre pobreza, a vulnerabilidade aparece como um conceito que nos remete à exposição ao risco e ao perigo, exclusão/inclusão, apartheid, periferização, segregação, entre outros (MARADOLA JR.; HOGAN, 2006), envolvendo a dificuldade de acesso a direitos básicos, tais como educação, saúde, cultura, lazer e trabalho, o que é comum na condição de pobreza e contribui para a manutenção da situação de vulnerabilidade à qual o pobre está submetido (ABRAMOVAY et al., 2002).

Por outro lado, divergindo dos conceitos acima apresentados, Castro e Abramovay (2005) nos estudos sobre o conceito de vulnerabilidade apontaram para uma concepção dialética, onde se busca enfocar as potencialidades dos sujeitos, no que tange ao enfrentamento das situações adversas. É neste sentido que se formula o conceito de vulnerabilidade positiva, que emerge quando os sujeitos aprendem, pelo vivido, a construir formas de resistência e enfrentamento das condições de risco, expressando o poder simbólico dos sujeitos de subverter as condições adversas. Sendo assim, para os autores, podemos falar de uma vulnerabilidade negativa - concepção tradicional -, representada pelos riscos e obstáculos ao desenvolvimento dos sujeitos, famílias e comunidades, e uma vulnerabilidade positiva, em que, consciente dos riscos, os sujeitos buscam uma ética de vida pautada na crítica

Fractal, Rev. Psicol., v. 30 - n. 2, p. 196-203, 2018 
social, que reafirma as possibilidades e recursos desenvolvidos e utilizados por estes sujeitos para enfrentar as situações de risco presentes no território.

Destarte, os territórios definem-se alicerçados nas identificações, nos vínculos afetivos, na participação do sujeito para a construção dos lugares, na história patrimonial, na história de vida das comunidades, nas relações de vizinhança (GÓIS, 2008), além de outros aspectos que estão na interface entre o micro e o macrossocial. Esta constatação auxilia-nos a compreender, por exemplo, o comportamento de sujeitos que mesmo residindo em áreas consideradas vulneráveis, recusam-se a sair de suas casas em nome da segurança de outra residência, uma vez que a segurança psicológica possibilitada pelo território conhecido e apropriado (BOMFIM, 2003), sobrepõe-se à segurança física prometida pela mudança para o espaço desconhecido.

Desta maneira, no território encontram-se os fatores que geram risco e perigo para os sujeitos, o que nos permite afirmar a espacialização da vulnerabilidade, e ao mesmo tempo os elementos necessários para que estas situações adversas sejam enfrentadas e, se não superadas completamente, ao menos minimizadas. No horizonte destas potencialidades, a afetividade aparece como categoria que vai na contramão da lógica vigente, apresentando-se como caminho para o enfrentamento das iniquidades e promoção de um compromisso ético-político, capaz de vincular o sujeito aos seus ambientes e à coletividade.

Referenciar a vulnerabilidade territorializada, dentro de uma proposta pautada na afetividade, implica trazer ao palco da discussão crítico-reflexiva, a investigação do quê, no território, promove alegria aos sujeitos e, por conseguinte, aumenta sua potência de agir, garantindo maior capacidade de enfrentamento diante das situações adversas, ou, por outro lado, daquilo que entristece as pessoas, despotencializando-as para o enfrentamento das dificuldades cotidianas. Desta maneira, o afeto aparece como fator orientador de teorias e práticas direcionadas aos territórios onde a vulnerabilidade se expressa, podendo ser apontado, inclusive na estima de lugar, como indicador da capacidade de enfrentamento das situações adversas.

Os lugares nos afetam potencializando-nos ou despotencializando-nos e neste sentido, como afirmam Bomfim et al. (2013, p. 337), os lugares

[...] podem ser um importante caminho para potencializar indicadores subjetivos de proteção ao jovem, como autoestima, autoeficácia e perspectiva de futuro, e consequentemente promover a diminuição de riscos e de vulnerabilidades socioambientais [...].

Concordando com os autores supracitados, entendemos por autoestima a avaliação que o sujeito faz de si mesmo, que deriva de sua relação com o meio, configurando um juízo de valor atribuído a si, pautado nos valores pessoais, e está atravessado pelas condições socioeconômicas e da rede de apoio social e afetiva a que o sujeito tem acesso (ANTONI; BARONE; KOLLER, 2007). A autoeficácia diz do quanto o sujeito se avalia capaz de enfrentar e superar a situação adversa, a partir da confiança em suas próprias capacidades, ela representa, de acordo com Bomfim et al. (2013), a confiança que o sujeito tem em si mesmo para enfrentar os desafios com que se depara. Relacionada a estes dois conceitos, a perspectiva de futuro garante a construção dos projetos de vida dos sujeitos, dando o senso de continuidade no tempo.

Como anteriormente citado, um dos resultados que nos interessa aqui destacar, da pesquisa destes autores, é a influência que os afetos relacionados aos lugares podem ter nos fatores de proteção descritos acima. Fica explícito, portanto, que a afetividade que emerge em territórios vulneráveis pode ser o fio condutor de estratégias de enfrentamento e proposição de políticas e ações de proteção, uma vez que, dentro da concepção dialética e integral do ser humano, intervir nos espaços é também reconfigurar o campo, gerando novos afetos que potencializem os sujeitos e aumentem a autoestima, a autoeficácia e garantam a perspectiva de futuro, de modo que os sujeitos possam se implicar positivamente com os lugares e com a coletividade.

\section{Considerações finais}

Com base no que foi apresentado, fica patente a importância do território na constituição da identidade dos sujeitos. Nesta dimensão, há de se considerar que o território é o lugar de vida, dos afetos, onde os sujeitos podem ser potencializados ou despotencializados, exercer poder, fazer trocas, sofrer e enfrentar as injustiças, construir suas histórias e a de sua sociedade (SANTOS, 1999). Assim sendo, a Psicologia Ambiental, disciplina que tomamos como fundamentação teórica deste artigo, debruçando-se sobre a complexidade deste tema, volta seu olhar também para as diversas formas de vulnerabilidade que podem estar presente nos territórios, entendendo que elas são espacializadas, que ocorrem no cotidiano concreto dos sujeitos.

Pensar o território e as vulnerabilidades nele presentes implica atentar às diversas dimensões que fragilizam os sujeitos, que os despotencializam, entristecendo-os e gerando diferentes formas de servidão, tanto nas relações micro como macrossociais. Além disso, denunciamos as desigualdades e iniquidades promotoras de vulnerabilidades, direcionando nossa atenção para os modos de enfrentamento engendrados pelos sujeitos e para as potencialidades do território, a fim de fomentarmos uma práxis pautada na vida e na libertação dos sujeitos (GÓIS, 2008).

Podemos afirmar que mesmo nos territórios mais vulneráveis, os sujeitos encontram meios de adaptação e enfrentamento cotidiano às situações de perigo real e risco eminente. Neste sentido, admitindo que as desigualdades somente podem ser observadas quando se desloca a análise do mundo abstrato e universal para o mundo particular dos indivíduos (GÜNTHER, A.; GÜNTHER, H., 1998), na análise das vulnerabilidades do território, há de se considerar os aspectos coletivos, econômicos, espaciais e afetivos. Temos, portanto, que o bem-estar social também se relaciona diretamente com o espaço do qual o sujeito faz uso (BERNAL; BONFIM; MUDO, 2009), com o intuito de compreender a maneira como os sujeitos se relacionam com o lugar e entre si, bem como as possibilidades de enfrentamento que os territórios proporcionam. 
Nossa proposição da afetividade como categoria de resistência à negação da vida e como caminho capaz de gerar modos de enfrentamento da situação adversa, pauta-se na concepção de que podemos, dentro de uma visão dialética, investigar e denunciar as relações e as práticas despotencializadoras, próprias da ideologia dominante, que geram servidão e tristeza. Do mesmo modo, na realidade multidimensional dos territórios, podemos identificar e fortalecer as relações e redes potencilaizadoras, promotoras da alegria e dos bons encontros. Dentro do conceito de vulnerabilidade, como foi exposto, coexistem o risco, o perigo e a capacidade de resposta dos sujeitos, e esta resposta é dada na vivência do território, quando os sujeitos se unem para enfrentar os problemas, quando estão potencializados o suficiente para abrirem-se ao encontro com o outro, estabelecendo relações solidárias. Como afirma Sawaia (2009, p. 370), “[...] são os afetos os responsáveis pela união dos esforços (conatus), em nos fazermos um, como se fôssemos uma única mente e um único corpo", e esta é a via pela qual os sujeitos que vivem em territórios vulneráveis buscam manter sua existência, seus sonhos e a felicidade. Isto não nos parece distante quando pensamos nas relações de vizinhança, nas redes de apoio social, no uso do espaço público das comunidades, no sentar-se nas calçadas ao fim da tarde, nas estratégias que os próprios sujeitos elaboram cotidianamente para resolver os problemas.

\section{Referências}

ABRAMOVAY, M.; et al. Juventude, violência e vulnerabilidade social na América Latina: desafios para políticas públicas. Brasília: UNESCO/BID, 2002.

ALENCAR, H. F.; BOMFIM, Z. A. C.; BARROCAS, R. L. L. Epistemologia ambiental na psicologia: pela emergência de um saber complexo. In: CONFERÊNCIA INTERNACIONAL DOS SETE SABERES, 2010, Fortaleza. Anais... Fortaleza: UECE, 2010. Disponível em: http://www.uece.br/setesaberes/ anais/pdfs/trabalhos/1111-07082010-172645.pdf. Acesso em: 12 set. 2015.

ANTONI, C.; BARONE, L. R.; KOLLER, S. H. Indicadores de risco e de proteção em famílias fisicamente abusivas. Psicologia: Teoria e Pesquisa, v. 23, n. 2, p. 125-132, abr./jun. 2007. Cross ${ }^{\text {Ref. }}$

ARAGONÉS, J. I.; AMÉRIGO, M. (Ed.). Psicología ambiental. Aspectos conceptuales y metodológicos. In: Psicología Ambiental. Madrid: Pirámide, 1998. p. 23-42.

BERNAL, C.; BONFIM, Z.; MUDO, E. Vulnerabilidade, violência e pobreza na região metropolitana de Fortaleza. In: COSTA, M. C. L.; DANTAS, E. W. C. (Org.). Vulnerabilidade socioambiental na região metropolitana de Fortaleza. Fortaleza: UFC, 2009. p. 245-271.

BOMFIM, Z. A. C. Protagonismo social da psicologia no campo da circulação humana. In: SEMINÁRIO NACIONAL DE PSICOLOGIA E POLÍTICAS PÚBLICAS: POLÍTICAS PÚBLICAS, PSICOLOGIA E PROTAGONISMO SOCIAL, 2., 2003, João Pessoa. Relatório... João Pessoa: CFP, 2003. Disponível em: https://site.cfp.org.br/publicacao/ii-seminrionacional-de-psicologia-e-polticas-pblicas. Acesso em: 12 nov. 2015.
BOMFIM, Z. A. C. Cidade e afetividade: estima e construção dos mapas afetivos de Barcelona e São Paulo. Fortaleza: UFC, 2010.

BOMFIM, Z. A. C. et al. Estima de lugar e indicadores afetivos: aportes da Psicologia Ambiental e Social para a compreensão da vulnerabilidade social juvenil em Fortaleza. In: COLAÇO, V. F. R.; CORDEIRO, A. C. F. (Org.). Adolescência e juventude: conhecer para proteger. São Paulo: Casa do Psicólogo, 2013. p. 317-341.

BOMFIM, Z. A. C. et al. Affective maps: validating a dialogue between qualitative and quantitative methods. In: MIRA, R. G.; DUMITRU, A. (Ed.). Urban Sustainability: innovative spaces, vulnerabilities and opportunities. Coruña: Institute of Psychosocial Studies and Research "Xoan Vicente Viqueira", 2014. p. 131-148.

CASTRO, M. G.; ABRAMOVAY, M. Juventudes no Brasil: vulnerabilidades negativas e positivas, desafiando enfoques de políticas públicas. In: PETRINI, J. C.; CAVALCANTI, V. R. S. (Org.). Família, sociedade e subjetividade: uma perspectiva multidisciplinar. Petrópolis, RJ: Vozes, 2005. p. 54-83.

CORRALIZA, J. A. Emoción y ambiente. In: ARAGONES, J. I.; AMÉRIGO, M. (Coord.). Psicología ambiental. Madrid: Pirâmide, 1998. p. 281-302.

FEITOSA, M. Z. S. Afetividade na residência integrada em saúde: o psicólogo no território de form "ação". 2014. 206f. Dissertação (Mestrado em Psicologia) - Universidade Federal do Ceará, Fortaleza, 2014.

GÓIS, C. W. L. Saúde comunitária: pensar e fazer. São Paulo: Hucitec, 2008.

GIULIANI, M. V. O lugar do apego nas relações pessoasambiente. In: TASSARA, E. T.; RABINOVICH, E. P.; GUEDES, M. C. (Ed.). Psicologia e ambiente. São Paulo: Educ, 2004. p. 89-106.

GÜNTHER, I. A.; GÜNTHER, H. Brasílias pobres, Brasílias ricas: perspectivas de futuro entre adolescentes. Psicologia: Reflexão Crítica, Porto Alegre, v. 11, n. 2, p. 191-207, 1998. Cross ${ }^{\text {Ref }}$

HAESBAERT, R. O mito da desterritorialização: do "fim dos territórios" à multiterritorialidade. Rio de Janeiro: Bertrand Brasil, 2004.

HALL, E. T. A dimensão oculta. Rio de Janeiro: Francisco Alves, 1966.

HELLER, A. Teoria de los sentimientos. Tradução de Francisco Cuso. 3. ed. México: Distribuiciones Fontamara. 1993.

ITTELSON, W. H. et al. Homem Ambiental. Série Textos de Psicologia Ambiental, n. 14. Tradução de J. Q. Pinheiro. Brasília: UnB, Laboratório de Psicologia Ambiental, 2005. p. $1-9$.

LANE, S. T. M. A Psicologia Social e uma nova concepção do homem para a Psicologia. In: LANE, S. T. M.; CODO, W. (Org.). Psicologia social: o homem em movimento. 13. ed. São Paulo: Brasiliense, 1984. p. 10-19.

MARADOLA JR., E.; HOGAN, D. J. As dimensões da vulnerabilidade. São Paulo em Perspectiva, v. 20, n. 1, p. 3343, jan./mar. 2006. Disponível em: http://produtos.seade.gov. br/produtos/spp/v20n01/v20n01_03.pdf. Acesso em: 23 set. 2015. 
MARTINS, A. K. S. Mapas afetivos táteis: vivências urbanas não visuais na cidade de Fortaleza. 2015. 161f. Dissertação (Mestrado em Psicologia) - Universidade Federal do Ceará, Fortaleza, 2015.

MOSER, G. Psicologia Ambiental. Estudos de Psicologia, Natal, v. 3, n. 1, p. 121-130, 1998. Cross ${ }^{\mathrm{Ref}}$

PINHEIRO, J. Q.; GÜNTHER, H; GUZZO, R. S. L. Psicologia Ambiental: área emergente ou referencial para um futuro sustentável? In: GÜNTHER, H.; PINHEIRO, J. Q.; GUZZO, R. S. L. (Org.). Psicologia Ambiental: entendendo as relações do homem com seu ambiente. 3. ed. Campinas, SP: Alínea, 2014. p. 5-13.

POL, E. La apropiación del espacio. In: IÑIGUEZ, L.; POL, E. (Org.). Cognición, representación y apropiación del espacio. Barcelona: Universitat de Barcelona, 1996. p. 45-21.

PONTE, A. Q. Afetividade de idosos de vida religiosa consagrada e a moradia na casa de saúde: projetos de vida e processo de estabilização residencial. 2010. 125 f. Dissertação (Mestrado em Psicologia) - Departamento de Psicologia, Programa de Pós-Graduação em Psicologia, Universidade Federal do Ceará, Fortaleza, 2010.

PROSHANSKY, H. M.; FABIAN, A. K.; KAMINOFF, R. Place-identity: physical world socialization of the self. Journal of Environmental Psychology, v. 3, p. 57-83, 1983. Cross ${ }^{\text {Ref. }}$

SANTOS, M. O dinheiro e o território. GEOgraphia, ano 1, $\mathrm{n}^{\mathrm{o}}$ 1, p. 7-13, 1999. Disponível em: http://www.geographia.uff. br/index.php/geographia/article/view/2/2. Acesso em: 23 set. 2015.

SANTOS, M. Da totalidade ao lugar. São Paulo: Edusp, 2005.

SAWAIA, B. B. O calor do lugar, segregação urbana e identidade. São Paulo em Perspectiva, São Paulo, v. 9, n. 2, p. 20-24, 1995. Disponível em: http://produtos.seade.gov.br/ produtos/spp/v09n02/v09n02_04.pdf. Acesso em: 18 set. 2015.

SAWAIA, B. B. Sílvia Lane. Rio de Janeiro: Imago, 2002.

SAWAIA, B. B. Fome de felicidade e liberdade. In: Centro de Estudos e Pesquisas em Educação, Cultura e Ação Comunitária (Ed.). Muitos lugares para aprender. São Paulo, SP: CENPEC/ Fundação Itaú Social/ Unicef, 2003. p. 53-63.

SAWAIA, B. B. (Org.). O sofrimento ético-político como categoria de análise da dialética exclusão/inclusão. In: $A s$ artimanhas da exclusão: análise psicossocial e ética da desigualdade social. 11 ed. Petrópolis, RJ: Vozes, 2011. p. 99119.

SPINOZA, B. Ética. Tradução de Tomaz Tadeu. 2. ed. 4. reimp. Belo Horizonte: Autêntica, 2015.

TUAN, Yi-Fu. Espaço e lugar: a perspectiva da experiência. Tradução de Lívia de Oliveira. São Paulo: DIFEL, 1983.

VALDIVIESSO, R. Contribuição para o conhecimento da territorialidade humana: o graffiti e o espaço territorial urbano. Dissertação (Mestrado)-Faculdade de Ciências, Universidade do Porto, Porto, 2006. Disponível em: http://hdl.handle. net/10216/64108. Acesso em: 25 out. 2015.

VÉRAS, M. P. B. Cidade, vulnerabilidade e território. Ponto e virgula, n. 7, p. 32-48, 2010. Disponível em: https://revistas. pucsp.br/index.php/pontoevirgula/article/view/13959/10282. Acesso em: 5 mar. 2015.

VIGOTSKI, L. S. Pensamento e Linguagem. 2. ed. São Paulo: Martins Fontes, 1998.

Fractal, Rev. Psicol., v. 30 - n. 2, p. 196-203, 2018
WISNER, B. Marginality and vulnerability: why the homeless of Tokyo don't 'count' in disaster preparations. Applied Geography, v. 18, n. 1, p. 25-33, 1998. Cross ${ }^{\text {Ref. }}$

ZANELLA, M. E.; DANTAS, E. W. C.; OLÍMPIO, J. L. S. A vulnerabilidade natural e ambiental do município de Fortaleza/ CE. Boletim Goiano de Geografia, Goiânia, v. 31, n. 2, p. 1327, jul./dez. 2011. Cross ${ }^{\text {Ref }}$

Recebido em: 25 de outubro de 2015 Aceito em: 24 de agosto de 2017 